\title{
GBEP
}

\section{Dinâmicas de grupo orientadas pelas atividades de estudo: desenvolvimento de habilidades e competências na educação profissional}

\author{
Taís Fim Alberti \\ Ilse Abegg \\ Márcia Rejane Julio Costa \\ Mauro Titton
}

\section{Resumo}

Explicita resultados de pesquisa sobre dinâmicas de grupo e sua contribuição para aquisição de conhecimentos teórico-práticos. Realizamos ações em uma escola pública federal, envolvendo estudantes do terceiro semestre do Curso Técnico em Administração de Empresas. Para coleta de dados, planejamos, implementamos e avaliamos sequência didática centrada em dinâmicas de grupos tematizadas pelos conteúdos curriculares. Utilizaram-se questionários abertos para avaliar se as dinâmicas de grupo poderiam se constituir em atividades de estudo desenvolvimentais. Os resultados sinalizam que dinâmicas de grupo podem se configurar como uma prática pedagógica inovadora para o ensino centrado no desenvolvimento de competências e habilidades. Concluímos que a aprendizagem mediante dinâmicas de grupo pode se efetivar não apenas no plano teórico, mas também integrada à capacidade de atuar tanto em situações conhecidas como nas não previstas, desde que trabalhadas em sintonia com o conteúdo teórico da disciplina, planejada em ações e finalidades a serem alcançadas.

Palavras-chave: teoria das atividades; dinâmica de grupo; educação profissional. 


\section{Abstract \\ Group dynamics guided by activities of study: development of skills and competencies in professional education}

The article shows the research results of group dynamics and their contribution to the acquisition of theoretical and practical knowledge. We carried out actions in a federal public school, involving students of the third semester of the technical course in Business Administration. We planned, implemented and assessed the didactic sequence, centered in group dynamics, based on curricular contents. We used open-ended questionnaires to assess whether the group dynamics could constitute developmental study activities. The results indicate that group dynamics can be configured as an innovative pedagogical practice for a teaching focused on the development of competencies and skills. We conclude that learning through group dynamics can be realized not only in theory, but also by integrating the ability to act both in familiar situations as well as in unforeseen ones, as long as these situations are considered in harmony with the theoretical content of the course, planned in actions and objectives to be achieved.

Keywords: activity theory; group dynamics; professional education.

\section{Introdução}

Neste artigo, apresentamos resultados de uma pesquisa-ação em que buscamos desenvolver uma sequência didática por meio de atividades de dinâmicas de grupo. Para embasar nossa prática com as atividades de dinâmicas de grupo e, com intuito de superar a visão destas como brincadeiras, orientamo-nos na construção e na proposta de dinâmicas de grupo embasados pela Teoria da Atividade (Davidov, 1988). Essa teoria orienta a construção de atividades de estudo planejadas, monitoradas, conduzidas e avaliadas para que o sujeito envolvido nelas se desenvolva tanto em termos intelectuais como sociopsicológicos.

Tendo em vista que a orientação teórica para a construção de atividades de estudo se aproxima das orientações dos Referenciais Curriculares Nacionais da Educação Profissional de Nível Técnico (Brasil. MEC, 2000), no que tange ao entendimento de "competências" elaboramos um questionário com a intenção de identificar se as atividades de grupo (dinâmicas de grupo) contribuíram para a aquisição dos conhecimentos teórico-práticos na formação do Técnico em Administração de Empresas. As atividades de pesquisa foram implementadas na disciplina de Desenvolvimento de Pessoas nos Processos de Gestão do referido curso, em uma Escola Técnica Federal vinculada à Universidade Federal de Santa Maria (UFSM). 
Para tal, desenvolvemos atividades de dinâmicas de grupo com o intuito de dialogar e problematizar conceitos de motivação, criatividade, trabalho em equipe, liderança, comunicação e persuasão, que fazem parte da ementa de conteúdos. Estas foram planejadas tendo em vista levar os estudantes a atuarem em torno de ações e operações, oportunizando a realização de atividades teórico-práticas, agindo e modificando o objeto de aprendizagem. As atividades tinham como foco conduzir os sujeitos ao alcance de novas estruturas em seu desenvolvimento e, ainda, à mobilização do que aprenderam na realização de novas tarefas, tendo condições de contextualizarem com seus conhecimentos prévios.

Dessa maneira, a formação profissional e tecnológica poderá possibilitar o desenvolvimento do pensamento teórico dos estudantes, o raciocínio e o conhecimento da organização conceitual necessária a sua formação. Com isso, poderemos pensar em um empowerment (Saito, 2001), tornando esses estudantes ativos, críticos, criativos e capacitados para o domínio do trabalho, não apenas no plano teórico, mas também em integração à capacidade de atuar tanto em situações conhecidas quanto nas não previstas, que exigem criatividade e rapidez.

Portanto, a escolarização profissional e tecnológica é um componente primordial da atividade humana orientada para o desenvolvimento integral do sujeito. Assim, acreditamos que uma proposta de trabalho que traga para o escopo da formação articulação entre teoria e prática mediante dinâmicas de grupo pode melhorar o conteúdo e os métodos de ensino e de formação, de modo que isso influencie qualitativamente o desenvolvimento psíquico e intelectual dos envolvidos.

Este artigo organiza-se na discussão teórica sobre os conceitos de atividade de estudo da perspectiva sócio-histórica, aproximando-a do conceito de competências discutido nos Referenciais Curriculares Nacionais da Educação Profissional de Nível Técnico. Na sequência, apresentamos a metodologia de trabalho, o desenvolvimento e os resultados da pesquisa. Nas conclusões, apontamos que, ao fazer as relações do conteúdo da ementa no planejamento e na implementação das atividades de dinâmicas de grupo, estas se tornaram fundamentais para desenvolver as competências e as habilidades mentais e socioafetivas específicas do contexto da profissão.

\section{Fundamentação teórica}

\section{Atividades de estudo e competências}

Na perspectiva sócio-histórica, para que o sujeito se desenvolva precisa realizar atividades. Para que o sujeito esteja em atividades, requer que sejam realizadas ações e operações direcionadas a um fim, as quais visam à produção de instrumentos que possibilitam estabelecer relação entre motivo e objetivo da atividade em si. 
Para Davidov (1988), a aprendizagem e a educação escolar são momentos de mudança essenciais na vida dos estudantes, pois nesse processo vivenciam obrigações que influenciam diretamente seu desenvolvimento. No processo de escolarização, o estudante assimila os fundamentos das formas mais desenvolvidas da consciência social, ou seja, a ciência, a arte, a moral, o direito, que estão ligados com a consciência e o pensamento teórico das pessoas. A assimilação dessas formas de consciência social e as formações espirituais correspondentes pressupõem que os escolares realizem uma atividade adequada - a atividade humana historicamente encarnada nelas -, a qual é chamada de atividade de estudo.

Conforme Davidov (1988), no processo de resolução de atividades de estudo, os estudantes aprendem os conhecimentos (competências) e as habilidades correspondentes aos fundamentos das formas de consciência social, como também desenvolvem as capacidades surgidas historicamente que estão na base da consciência e do pensamento teórico, ou seja, a reflexão, a análise e o experimento mental. Isso significa dizer que os conteúdos da atividade de estudo são os conhecimentos teóricos ou científico-tecnológicos.

A atividade de estudo é, portanto, o movimento de formação do pensamento teórico, assentado na reflexão, na análise e no planejamento, que conduz ao desenvolvimento psíquico (Davidov, 1988). Para que ocorra esse movimento de formação do pensamento teórico, é preciso que no processo de dinâmicas de grupo se criem motivos cognoscentes para que os estudantes desenvolvam a atividade de estudo, tendo em vista seus pressupostos.

A partir desses pressupostos da teoria sócio-histórica, a atividade de estudo é composta por um conteúdo específico dirigido ao objeto. Já que se tem uma preocupação em relação à aquisição do conhecimento teórico, este precisa ser organizado, sistematizado e intencional. Esse conteúdo tem uma estrutura especial, a qual requer planejamento definido com as finalidades a serem alcançadas, ou seja, as atividades de estudo não estão disponíveis de forma aleatória. Em seu planejamento, contemplamos ações de estudo (estudante) e ações de ensino (docente) para que se alcance desenvolvimento dos sujeitos em processos de formação. Na composição de uma atividade de estudo, trabalhamos com tarefas dialógicoproblematizadoras, a fim de que nesse processo busquemos o ser mais (Freire, 1987). Nesse contexto, o professor planeja, de forma sistematizada, a organização conceitual que será trabalhada na dinâmica de grupo e problematiza o objeto de ensino-aprendizagem, levando os estudantes a desenvolverem ações e operações para a apropriação do conhecimento teórico necessário a sua formação psicointelectual, configurando-se uma atividade de estudo desenvolvimental, ou seja, gerando transformações nos sujeitos atuantes desse processo.

As Diretrizes Curriculares Nacionais para a Educação Profissional de Nível Técnico (Brasil. CNE/CEB, Resolução $n^{\circ} 4$, 1999) destacam entre os princípios norteadores da educação profissional de nível técnico, o 
desenvolvimento de competências para a laborabilidade. Tais competências são classificadas em três: básicas, profissionais gerais e profissionais específicas. Assim, as atividades de estudo organizadas na forma de dinâmicas de grupo precisam gerar desenvolvimento que perpassa por tais competências, propiciando habilidades para o mundo do trabalho.

O conceito de competências articula conhecimentos, habilidades e valores/atitudes. De acordo com os Referenciais Curriculares Nacionais da Educação Profissional de Nível Técnico, competência é entendida da seguinte forma:

As competências enquanto ações e operações mentais articulam os conhecimentos (o saber, as informações articuladas operatoriamente), as habilidades (psicomotoras, ou seja, o saber fazer elaborado cognitivamente e socioafetivamente) e os valores, as atitudes (o saber ser, as predisposições para decisões e ações, construídas a partir de referenciais estéticos, políticos e éticos), constituídos de forma articulada e mobilizados em realizações profissionais com padrões de qualidade requeridos, normal ou distintivamente, das produções de uma área profissional. (Brasil. MEC, 2000, p. 10).

Tendo como base esses referenciais, aproximam-se os conceitos de atividade de estudo e competências, pois as duas têm como princípio a aquisição dos conhecimentos teóricos (conhecimento - ações mentais), que devem envolver os estudantes em ações e operações na resolução da atividade (habilidades - saber fazer), e, ao final do processo, espera-se que uma atividade de estudo gere não apenas a aquisição dos conhecimentos teóricos, mas uma transformação do próprio sujeito atuante, ou seja, uma transformação em relação aos valores e atitudes do sujeito (saber ser). Assim, podemos sistematizar as relações entre a atividade de estudo e as competências (Quadro 1).

\section{Quadro1 - Relações entre Atividades de Estudo e Competências}

\begin{tabular}{|l|l|l|l|}
\hline Competência & $\begin{array}{l}\text { Conhecimento } \\
\text { (saber) }\end{array}$ & $\begin{array}{l}\text { Habilidades } \\
\text { (saber fazer) }\end{array}$ & $\begin{array}{l}\text { Valores e atitudes } \\
\text { (saber ser) }\end{array}$ \\
\hline $\begin{array}{l}\text { Atividade de } \\
\text { estudo }\end{array}$ & $\begin{array}{l}\text { Conhecimento } \\
\text { teórico }\end{array}$ & $\begin{array}{l}\text { Ações e } \\
\text { operações }\end{array}$ & $\begin{array}{l}\text { Transformação do } \\
\text { sujeito }\end{array}$ \\
\hline
\end{tabular}

Fonte: Sistematização teórica da pesquisa.

\section{Dinâmica de grupo como uma atividade de estudo na educação profissional}

De acordo com a Sociedade Brasileira de Dinâmica de Grupo (2006, p. 1), "dynamis é uma palavra de origem grega que significa força, energia, ação". A expressão dinâmica de grupo teve sua origem em um artigo publicado por Kurt Lewin, em 1944, ano em que passou a integrar o Instituto de Tecnologia de Massachusetts (MIT), onde criou o Centro de Pesquisa em Dinâmica de Grupos (Research Center for Group Dynamics). Para Lewin (apud Coltro, 2006, p. 24), a dinâmica de grupo é o "estudo 
das forças que agem no seio dos grupos, suas origens, consequências e condições modificadoras do comportamento do grupo". Assim, caracteriza um grupo como sendo "um todo dinâmico" (p. 33), em que mudanças em uma das partes do grupo interferem nos comportamentos dos demais participantes.

Segundo Perpétuo e Gonçalves (2005, p. 2),

a dinâmica de grupo constitui um valioso instrumento educacional que pode ser utilizado para trabalhar o ensino-aprendizagem quando optase por uma concepção de educação que valoriza tanto a teoria quanto a prática e considera todos os envolvidos neste processo como sujeitos.

Dessa forma, a aprendizagem acontece em um processo coletivo, em que o encontro de pessoas promove a construção do saber em conjunto, estimula a capacidade criadora, mexe com a desenvoltura dos participantes, melhora sua produtividade, mostra a possibilidade de transformações, estimula o trabalho em equipe e pode melhorar as relações interpessoais e intrapessoais, possibilitando um caminho para se interferir na realidade, modificando-a (Sociedade..., 2006). Em cursos técnicos de administração de empresas, busca-se exatamente isso: ensinar comportamentos novos relacionados com o desenvolvimento dos processos de gestão de pessoas.

Nesse mesmo sentido, Kolb (apud Silva, 2008, p. 9) observa que dinâmica de grupo é "uma situação simulada, desenvolvida para se criar experiências para aqueles que aprendem, serve para iniciar o seu próprio processo de investigação e aprendizado". Dessa forma, propomos dinâmicas de grupo no processo de ensino-aprendizagem no âmbito da disciplina de "Desenvolvimento de pessoas nos processos de gestão" no Curso Técnico em Administração, pois a dinâmica de grupo é um instrumento em que se torna possível vivenciar uma experiência significativa para os sujeitos envolvidos no grupo de trabalho.

Por outro lado, Perpétuo e Gonçalves (2005, p. 2) ponderam que a dinâmica de grupo no processo coletivo não deve ser absolutizada ou subestimada. Para as autoras, sua utilização deve responder a

objetivos específicos de uma determinada estratégia educativa, no sentido de estimular a produção do conhecimento e a recriação deste conhecimento tanto no grupo/coletivo quanto no indivíduo/singular, uma vez que a técnica da dinâmica não é um fim, mas um meio - é uma ferramenta a ser usada.

Para que a dinâmica de grupo atinja esses objetivos, faz-se necessário um planejamento daquilo que se pretende trabalhar em aula com os estudantes (modalidade de dinâmica que se utilizará), considerando o conhecimento que se tem intenção de que o estudante aprenda. Além de ter presente no planejamento intenção, organização e sistematização dos conceitos, as atividades de estudo com dinâmica de grupo devem primar por espaços que levem o estudante a expressar-se socialmente, dialogando com os demais integrantes, ouvindo seus pontos de vista, 
compartilhando ideias e administrando conflitos que fazem parte desse processo. A sala de aula é um espaço privilegiado para a construção do conhecimento com o outro, inclusive problematizando situações que conduzam ao desenvolvimento de competências e habilidades requeridas na prática profissional.

Nessa perspectiva, está o ensino técnico de nível médio, pois "objetiva garantir ao cidadão o direito ao permanente desenvolvimento de aptidões para a vida produtiva e social" (Brasil. CNE/CEB, Resolução nº 4, 1999, p. 1). Segundo os Referenciais Curriculares Nacionais para a Educação Profissional de Nível Técnico, a laborabilidade ou a trabalhabilidade é entendida como componente da dimensão produtiva da vida social e, portanto, da cidadania, sendo objetivo primordial da educação profissional (Brasil, 2000). Assim, as dinâmicas de grupo nos cursos técnicos podem potencializar a relação teoria-prática do mundo do trabalho dos estudantes.

Nesse contexto, precisávamos trabalhar habilidades referentes à compreensão do caráter estratégico do comportamento e aos principais elementos facilitadores das relações interpessoais do futuro Técnico em Administração. As bases tecnológicas referentes a essas habilidades estavam alicerçadas no trabalho relativo à importância das pessoas nas organizações e ao comportamento das pessoas e suas relações com o trabalho e com a produtividade. Além dessas bases, ainda tínhamos que desenvolver os conceitos, já citados anteriormente, de motivação, criatividade, trabalho em equipe, liderança, comunicação, persuasão, confiança. Considerando esses componentes curriculares, e embasados pela perspectiva teórica das atividades de estudo, optamos pelo trabalho com dinâmicas de grupo para que os estudantes experienciassem situações em que pudessem criar, dramatizar, resolver problemas, argumentar, persuadir, levando a situações que se aproximassem das questões reais dos profissionais técnicos em administração, como também a um autoconhecimento para discernir sobre suas questões subjetivas e sobre de que modo essas questões pessoais influenciam sua vida no trabalho.

Além dessas questões, a dinâmica de grupo traz um componente de ordem motivacional, especialmente no momento que oportuniza aos estudantes vivenciarem situações próximas a sua atuação como futuro profissional da área de administração (em que dinâmicas de grupo são um componente, não só da ordem de seleção e recrutamento, mas também como opção de trabalho para muitas empresas que queiram melhorar questões de clima organizacional, motivação, relações humanas e outros). Ou seja, na área de administração, é possível explorar aspectos lúdicos do ser humano em confronto com as rotinas do cargo/profissão. Além disso, a dinâmica oportuniza a simulação de realidades organizacionais em situações diferenciadas, ocupando lugar especial na formação e na gestão de pessoas (Balbinot et al, 2005). Segundo Alberto et al (2011, p. 2), as dinâmicas de grupos levam os

indivíduos a participarem e terem responsabilidades e a desenvolverem o espírito de iniciativa. É também um veículo de socialização à medida 
que proporciona a convivência. Contribui para a formação e, sobretudo, para expressão de ideias lógicas, objetivas e coerentes.

Assim, concordamos com Silva (2008, p. 91), quando diz que

a dinâmica de grupo se torna uma atividade essencialmente educativa, uma vez que esteja, desde logo, inserta em um contexto que contemple propósitos educacionais e que tome em conta não apenas as necessidades dos participantes, mas também e, sobretudo, a identidade do grupo em que é aplicada.

Além desses propósitos, não podemos deixar de considerar que, em se tratando de um processo educacional, a dinâmica a ser trabalhada não pode perder de vista a organização conceitual que faz parte da formação escolar.

Esses pressupostos têm a intenção de superar a visão em relação a práticas com dinâmicas de grupo como apenas uma "brincadeira". Portanto, para que seja efetivamente superada essa visão banalizada do trabalho do professor com dinâmica de grupo, esta deverá ser compreendida como uma atividade de estudo e, necessariamente, ser planejada, orientada, monitorada e avaliada, atribuindo um significado ao que é experienciado no trabalho.

Tavares e Lira (2001) classificam as dinâmicas de grupo em quatro tipos: a) dinâmicas de apresentação: são aquelas que visam eliminar as tensões e proporcionar um ambiente de cordialidade e aceitação mútua; b) dinâmicas de descontração: são aquelas que têm o objetivo de descontrair, eliminando a monotonia e proporcionando o despertar do interesse do grupo por temas específicos com devida liberdade em seus comentários; c) dinâmicas de aplicação: são as que contribuem para a aquisição do conteúdo, potencializando a assimilação deste pelos participantes; d) dinâmicas de avaliação: é o tipo que contribui para que, após as atividades, os participantes avaliem o desenvolvimento do estudo, assim como a apresentação de sugestões para possíveis melhoramentos.

Trabalhamos com dinâmicas de apresentação e de aplicação, haja vista que no início do semestre era preciso desenvolver um clima de descontração e eliminar as tensões, compartilhando nossas expectativas, apresentando-nos aos colegas e contando a história dos nossos nomes. Cabe destacar que atividades de estudo com dinâmicas de apresentação também são tematizadas por conteúdos pertinentes à formação de competências profissionais gerais, no âmbito de cursos técnicos em administração, uma vez que se tem como objetivo formativo problematizar conceitos de motivação e comunicação, assim como questões relacionadas ao desenvolvimento sociopsicológico, ou seja, a relações interpessoais.

Na sequência, as dinâmicas de aplicação nos possibilitaram a articulação entre as dinâmicas e os conteúdos referentes às competências específicas, configurando-se em atividades de estudo, pois buscamos nos planejamentos contemplar cada uma das bases tecnológicas necessárias à formação do estudante, aproximando-as da prática profissional. Os estudantes envolveram-se em ações e operações motivados pelos 
desafios que cada dinâmica trazia aos processos de criação. Assim, implementamos sequência didática de ensino-aprendizagem centrada no desenvolvimento de competências e habilidades. Se as competências são caracterizadas pela capacidade de, por meio de esquemas mentais ou de funções operatórias, mobilizar, articular e colocar em ação valores, conhecimentos e habilidades, isso requer, necessariamente, "adotar uma prática pedagógica que propicie, essencialmente, o exercício contínuo e contextualizado desses processos de mobilização, articulação e aplicação" (Brasil. MEC, 2000, p. 31). Nesse contexto, as atividades de dinâmica de grupo podem sim ser consideradas uma abordagem metodológica diferenciada para o desenvolvimento de competências específicas e gerais do técnico da área de administração de empresas.

\section{Metodologia e desenvolvimento}

O trabalho foi desenvolvido como prática de estágio supervisionado III do curso especial de graduação para formação de professores para o ensino profissional, cumprindo 30 horas/aula. As dinâmicas de grupo foram planejadas juntamente com a professora da disciplina e supervisionadas pela orientadora de estágio. A experiência com a qual nos envolvemos quando da elaboração e da execução de dinâmicas de grupo aconteceu no âmbito da disciplina "DESO30 - Atuar no desenvolvimento dos aspectos comportamentais da gestão de pessoas". As dinâmicas foram trabalhadas com a turma do curso Técnico em Administração de Empresas, conforme referido anteriormente. O curso era noturno e constavam matriculados 61 estudantes; porém, compareceram às aulas 50 alunos. A faixa etária predominava entre 20 e 30 anos e o público era bem diversificado: tínhamos estudantes trabalhadores, outros cursando concomitante ao curso técnico o ensino superior. Alguns se encontravam na faixa etária dos 40 aos 50 anos, e predominavam estudantes do sexo feminino.

O objetivo da pesquisa era investigar se as atividades de dinâmica de grupo poderiam contribuir para aquisição dos conhecimentos teóricopráticos na formação de técnicos em administração de empresas, desenvolvendo as competências necessárias aos profissionais dessa área. A metodologia empregada para esse trabalho foi a pesquisa-ação, pois nos envolvemos no processo de ação-reflexão-ação, diante de cada situação abordada nas dinâmicas de grupo, trabalhando a tomada de decisão, visando à transformação dos sujeitos envolvidos no processo e à compreensão de seus comportamentos, atitudes e valores diante do que concerne ao profissional da área e problematizando os conceitos trabalhados em cada dinâmica.

De acordo com Franco (2005), a pesquisa-ação teve suas origens nos trabalhos de Kurt Lewin, em 1946, num contexto de pós-guerra, dentro de uma abordagem de pesquisa experimental, de campo. Suas pesquisas iniciais tinham por finalidade a mudança de hábitos alimentares da população e também de atitudes dos americanos em face dos grupos éticos minoritários. Segundo a autora suas pesquisas pautavam-se por um conjunto de valores, tais como: 
a construção de relações democráticas; a participação dos sujeitos; o reconhecimento de direitos individuais, culturais e étnicos das minorias; a tolerância a opiniões divergentes; e ainda a consideração de que os sujeitos mudam mais facilmente quando impelidos por decisões grupais. Suas pesquisas caminhavam paralelamente a seus estudos sobre a dinâmica e o funcionamento dos grupos. (Franco, 2005, p. 485).

Optamos por essa metodologia posto que pesquisa e ação podem caminhar juntas, quando se pretende a transformação da prática, especialmente nesse momento em que estamos vivenciando a prática de estágio docente e precisamos refletir, também, em torno de nossa atuação. No entanto, de acordo com Franco (2005), a direção, o sentido e a intencionalidade dessa transformação serão o eixo da caracterização da abordagem da pesquisa-ação. Essa metodologia proporciona e enriquece o processo de pesquisar, transformar e construir conhecimento coletivo. O ponto central é a preocupação com o processo em si e não com o produto. Para tanto, torna-se essencial a interação entre o pesquisador e o grupo pesquisado, proporcionando espaço onde os sujeitos falem por si mesmos, desvelando a sua realidade, interagindo e ensinando-se mutuamente (Franco, 2005).

Com o objetivo de estimular a participação ativa e consciente e de dar suporte ao processo educativo, vários métodos e técnicas, dinamizadoras e motivadoras, foram utilizadas para o envolvimento do grupo. Dessa forma, desenvolvemos os seguintes passos: planejamento das dinâmicas de grupo; ação (desenvolvimento das dinâmicas de grupo envolvidas por ações e operações no contexto de formação de técnicos em administração); observação, acompanhamento e orientação no desenvolvimento das dinâmicas; reflexão (diálogo com todos os envolvidos em torno das questões trazidas nas dinâmicas de grupo, buscando interpretar a forma como se deu o desenvolvimento de toda a prática).

Esses passos partiam de um problema - implementar dinâmicas de grupo que gerassem desenvolvimento psíquico e intelectual nos sujeitos em processos de formação profissional e tecnológica - em que instrumentos e técnicas foram usados para que essas dinâmicas se configurassem em atividades de estudo. Posteriormente, foi delineado um plano de ação (que se baseava em objetivos, em um processo de acompanhamento e controle da ação planejada e no relato concomitante desse acompanhamento). Buscamos com o grupo solucionar o problema, com o intuito de que os envolvidos desenvolvessem um aprendizado de pesquisa da própria realidade para conhecê-la melhor e vir a atuar mais eficazmente sobre ela, transformando-a. Assim, esses passos contemplaram um ciclo espiralado para desenvolver o processo de ensino-aprendizagem, pois orientavam desde o planejamento até a avaliação, produzindo um movimento no contexto da ação-reflexão-ação.

No Quadro 2, especificamos as atividades de dinâmicas de grupo trabalhadas e os conteúdos contemplados em cada uma delas, tendo em vista o desenvolvimento profissional do técnico em administração em suas habilidades e competências: 


\section{Quadro 2 - Bases Tecnológicas Contempladas com as Atividades de Dinâmicas de Grupo}

\begin{tabular}{|c|c|}
\hline Atividades de estudo & Bases tecnológicas \\
\hline $\begin{array}{l}\text { Dinâmica de apresentação } \\
\text { - significados dos nomes }\end{array}$ & $\begin{array}{l}\text { O comportamento das pessoas e suas relações } \\
\text { com o trabalho e com a produtividade. } \\
\text { Observamos os comportamentos nas falas dos } \\
\text { estudantes, na forma de se expressar e ouvir } \\
\text { o outro e debatemos essas circunstâncias no } \\
\text { desenvolvimento profissional. }\end{array}$ \\
\hline Técnica da sanfona & $\begin{array}{l}\text { A importância das pessoas nas organizações. } \\
\text { Observar e expressar as qualidades dos colegas } \\
\text { em termos de habilidades pessoais e profissionais } \\
\text { (relacionadas com a área da administração); } \\
\text { comentar tais qualidades e sua importância no } \\
\text { desempenho da profissão. }\end{array}$ \\
\hline Resolução de problemas & $\begin{array}{l}\text { Avaliação do comércio varejista de rua e shopping } \\
\text { centers em Santa Maria. } \\
\text { Levantar e discutir as problemáticas do } \\
\text { comércio de Santa Maria e construir formas de } \\
\text { intervenção nessas problemáticas em grupos para } \\
\text { apresentação e defesa aos demais colegas. }\end{array}$ \\
\hline Desenho compartilhado & $\begin{array}{l}\text { Criatividade; trabalho compartilhado, colaboração, } \\
\text { trabalho em equipe. }\end{array}$ \\
\hline Características pessoais & Elementos facilitadores das relações interpessoais. \\
\hline $\begin{array}{l}\text { Dramatização de } \\
\text { resolução de problemas }\end{array}$ & $\begin{array}{l}\text { Heurística de resolução de problemas; } \\
\text { trabalho em equipe, criatividade, pensamento } \\
\text { crítico, avaliação de soluções tomadas e suas } \\
\text { consequências. }\end{array}$ \\
\hline Vendendo o impossível & $\begin{array}{l}\text { Confiança, criatividade, persuasão, comunicação, } \\
\text { argumentação, trabalho com objeções. }\end{array}$ \\
\hline Propósito de vida & Valores, atitudes, relações interpessoais. \\
\hline
\end{tabular}

Fonte: Dados da pesquisa.

Portanto, por meio da pesquisa-ação, investigamos e desenvolvemos com os estudantes dinâmicas de grupo que permitissem a apropriação da cultura social vigente no tocante à sua formação e o desenvolvimento no âmbito da formação profissional técnica. Ao final do estágio, os estudantes foram convidados a responder um questionário aberto, que foi construído tendo como base a ementa da disciplina, os referenciais da Teoria da Atividade que embasa o conceito de atividade de estudo (Davidov, 1988; Leontiev, 1978) e os Referenciais Curriculares Nacionais da Educação Profisisonal de Nível Técnico (Brasil. MEC, 2000), que também nos proporcionaram a investigação do significado de competência.

A construção do questionário primou por investigar se as dinâmicas de grupo se configuravam em atividades de estudo desenvolvimentais no âmbito da formação profissional e sua análise levou em consideração as categorias que orientam o conceito de competências: conhecimento, habilidades e valores/atitudes. 


\section{Análises e resultados}

Realizamos o questionário durante o horário da aula e todos os alunos presentes o responderam, totalizando 37 participantes. Os estudantes foram informados sobre o objetivo do questionário, bem como orientados de que não precisariam identificar-se. Antes da aplicação, realizamos a leitura para verificar se existiam dúvidas em relação a algum termo usado, esclarecendo-as.

Dos 37 participantes, apenas 9 nunca haviam participado de atividades de dinâmicas de grupo em aula. Ao questionarmos de qual dinâmica de grupo teve mais interesse em participar e a que considerou mais significativa para a aprendizagem, 12 estudantes responderam que foi a dinâmica "Vendendo o impossível"; em seguida, apareceu a dinâmica do "Desenho compartilhado", com 6 menções, e em terceiro, com 3 citações cada uma, as dinâmicas de: "Dramatização de resolução de problemas", "Técnica da sanfona" e "Relaxamento e concentração". Por fim, com apenas duas menções, aparecem as técnicas de apresentação: "Significado do nome" e "Apresentação de cada colega".

$\mathrm{Na}$ análise das categorias, relacionamos cada uma delas com uma determinada pergunta do questionário (Quadro 3):

\section{Quadro 3 - Relação Categoria x Questionário}

\begin{tabular}{|l|l|}
\hline \multicolumn{1}{|c|}{ Categorias } & \multicolumn{1}{c|}{ Pergunta relacionada } \\
\hline $\begin{array}{l}\text { Categoria } 1= \\
\text { conhecimento }\end{array}$ & $\begin{array}{l}\text { Que conteúdos (das bases tecnológicas) necessários } \\
\text { à formação do técnico em administração você } \\
\text { considera que foram trabalhados durante a disciplina } \\
\text { de "Desenvolvimento de pessoas nos processos de } \\
\text { gestão"? }\end{array}$ \\
\hline $\begin{array}{l}\text { Categoria } 2= \\
\text { habilidades }\end{array}$ & $\begin{array}{l}\text { Descreva como as atividades de dinâmicas contribuíram } \\
\text { para o seu desenvolvimento profissional. }\end{array}$ \\
\hline $\begin{array}{l}\text { Categoria 3 }= \\
\text { valores/atitudes }\end{array}$ & $\begin{array}{l}\text { Como foi para você vivenciar esse tipo de prática de } \\
\text { ensino? Você gostou? Por quê? Das dinâmicas que } \\
\text { foram propostas, de qual você teve mais interesse } \\
\text { em participar? Qual foi mais significativa para a sua } \\
\text { aprendizagem? Por quê? }\end{array}$ \\
\hline
\end{tabular}

Fonte: Dados da pesquisa

Assim, para saber se os conhecimentos foram contemplados, analisamos a questão do questionário relacionando-a com as categorias. No entanto, não deixamos de contemplar a leitura do todo, uma vez que as categorias também poderiam ser encontradas em outras questões.

Para melhor visualizar os dados coletados, optamos por evidenciálos no Quadro 4. Apresentamos os resultados demonstrando as relações entre as categorias de análise emergidas dos conceitos de atividade de estudo e competências (conforme Quadro 1). No Quadro 4, apresentamos os questionários com os elementos que contemplam todas as categorias analisadas. Ainda, apontamos que os estudantes conseguiram fazer a 
relação teoria-prática (apropriação do conhecimento), demonstrando desenvolvimento psíquico-intelectual, não apenas no âmbito profissional, mas também no pessoal (transformação do sujeito em termos de valores e atitudes). Diante disso, as análises nos mostram que as dinâmicas de grupos tornaram-se atividades de estudo desenvolvimentais.

\section{Quadro 4-Questionários com as Categorias Conhecimento, Desenvolvimento Profissional e Pessoal}

\begin{tabular}{|l|l|l|l|}
\hline \multicolumn{1}{|c|}{ Questionários } & $\begin{array}{c}\text { Categoria 1 - } \\
\text { Conhecimento (ações e } \\
\text { operações mentais) }\end{array}$ & $\begin{array}{l}\text { Categoria 2 - } \\
\text { Resolução da } \\
\text { atividade - habili- } \\
\text { dades (saber fazer) }\end{array}$ & $\begin{array}{c}\text { Categoria 3 - valores e } \\
\text { atitudes }\end{array}$ \\
\hline Q2, Q6 & $\begin{array}{l}\text { Comportamer ser) } \\
\text { pessoas nas organizações, } \\
\text { criatividade, persuasão. }\end{array}$ & $\begin{array}{l}\text { Desenvoltura ante os } \\
\text { colegas; } \\
\text { argumentação. }\end{array}$ & $\begin{array}{l}\text { Autoconhecimento; relações } \\
\text { interpessoais. }\end{array}$ \\
\hline $\begin{array}{l}\text { Q3, Q5, Q9, Q10, } \\
\text { Q12, Q15, Q16, } \\
\text { Q19, Q20, Q21 }\end{array}$ & $\begin{array}{l}\text { Criatividade, motivação, } \\
\text { comunicação, persuasão, } \\
\text { liderança. }\end{array}$ & $\begin{array}{l}\text { Trabalho em equipe; } \\
\text { argumentação. }\end{array}$ & $\begin{array}{l}\text { Relações interpessoais; } \\
\text { comprometimento. }\end{array}$ \\
\hline Q4, Q7, Q11, Q14, & $\begin{array}{l}\text { Comportamento das } \\
\text { pessoas nas organizações; } \\
\text { comunicação, persuasão, } \\
\text { criatividade, liderança. }\end{array}$ & $\begin{array}{l}\text { Tomada de decisões; } \\
\text { planejamento e } \\
\text { empreendedorismo; } \\
\text { resolução de problemas. }\end{array}$ & $\begin{array}{l}\text { Postura social, } \\
\text { espontaneidade, confiança } \\
\text { em si. }\end{array}$ \\
\hline Q8, Q17 & Comunicação e persuasão. & $\begin{array}{l}\text { Concentração } \\
\text { e agilidade, } \\
\text { argumentação. }\end{array}$ & $\begin{array}{l}\text { Valorização do grupo a que } \\
\text { pertence, autoconhecimento, } \\
\text { reflexão pessoal x profissional. }\end{array}$ \\
\hline Q18 & $\begin{array}{l}\text { Comportamento das } \\
\text { pessoas nas organizações. }\end{array}$ & $\begin{array}{l}\text { Trabalho em equipe. } \\
\text { Relações interpessoais; } \\
\text { autoconhecimento. }\end{array}$ \\
\hline
\end{tabular}

Fonte: Dados da pesquisa.

Nota: (1) Autoconhecimento: superação da timidez, exposição de ideia e críticas, confiança em si, espontaneidade, autorreflexão diante de novas situações;

Relações interpessoais: disposição para o diálogo, respeito à opinião do outro, convívio com as diferenças;

Comprometimento: valorização do grupo, disposição para realizar a atividade, colaboração, determinação;

Postura social: ser tolerante, respeitar o outro, rever atitudes no trabalho.

Na sequência, apresentamos o Quadro 5, em que conseguimos identificar apenas as categorias de conhecimento e valores/atitudes. $\mathrm{Na}$ análise dos questionários, percebemos que os estudantes não conseguiram descrever como os conteúdos citados geraram desenvolvimento profissional. Apenas descreveram como os conteúdos ajudaram em situações de ordem pessoal, referentes ao relacionamento com o outro, à autoavaliação do comportamento e à superação da timidez, conforme demonstra o Quadro 5.

Embora não identifiquemos as habilidades referentes ao saber fazer no Quadro 5, verificamos em ambos (Quadros 4 e 5) que, além dos conteúdos das bases tecnológicas, desenvolveram-se atitudes para o trabalho em equipe. Atualmente, esse tipo de prática é fundamental nos processos educacionais, tendo em vista a necessidade de superar atitudes e práticas individualistas e trabalhar de forma mais colaborativa, compartilhando ideias, projetos e propostas com o outro. Acreditamos que nesse aspecto conseguimos levar os estudantes a uma reflexão-ação em relação a essa 
prática, pois, nos questionários, muitos mencionaram que tiveram que trabalhar a disposição (querer) para o diálogo com o outro, ouvindo as diferentes opiniões para se chegar a um acordo que fosse comum a todos os integrantes do grupo, na hora de resolver uma determinada situação colocada pela dinâmica e que deveria ser debatida no grupo.

\section{Quadro 5 - Questionários com as Categorias Conhecimento e Desenvolvimento Pessoal}

\begin{tabular}{|l|l|l|}
\hline \multicolumn{1}{|c|}{ Questionário } & \multicolumn{1}{|c|}{$\begin{array}{c}\text { Conhecimento (ações e operações } \\
\text { mentais) }\end{array}$} & \multicolumn{1}{|c|}{ Valores e atitudes (saber ser) } \\
\hline Q1 & $\begin{array}{l}\text { Comportamento das pessoas nas } \\
\text { organizações; trabalho em equipe; } \\
\text { criatividade. }\end{array}$ & Relações interpessoais e autoconhecimento. \\
\hline Q13, Q26 & Comunicação; liderança, motivação. & Autoconhecimento. \\
\hline Q23 & Criatividade. & Relações interpessoais. \\
\hline Q27 & $\begin{array}{l}\text { Comportamento das pessoas nas } \\
\text { organizações; comunicação; criatividade. }\end{array}$ & Autoconhecimento. \\
\hline Q28 & $\begin{array}{l}\text { Comunicação. } \\
\text { Comportamento das pessoas nas } \\
\text { organizações; criatividade; persuasão. }\end{array}$ & Relações interpessoais. \\
\hline
\end{tabular}

Fonte: Dados da pesquisa.

Outro aspecto relevante na prática do técnico em administração diz respeito às questões mais subjetivas referentes à comunicação (timidez) que está relacionada ao autoconhecimento. Tivemos diversos relatos que esse tipo de prática ajudou a superar essa dificuldade que muitos de nossos estudantes apresentam para falar e se expressar em público. Observamos isso na prática da venda do produto impossível, que não tinha como intenção a dramatização, mas em que surpreendentemente os estudantes se organizaram de forma a não só criar slogan do produto, mas também dramatizar a venda desse produto com fotos, declaração de pessoas que haviam comprado, gerentes de vendas, gerente de marketing e outras situações que eles criaram para tornar o produto impossível algo familiar e aceito pelos clientes, que eram seus colegas de turma.

Cabe ressaltar que não foi possível classificar dez questionários em nenhuma das categorias, pois não identificamos indícios de desenvolvimento pessoal ou profissional que correspondessem à concepção de competências trabalhada. Percebemos nesses questionários que os sujeitos não compreenderam o que as questões solicitavam, fugindo do foco das perguntas.

\section{Conclusão}

Concluímos que para a construção de competências (conhecimento, habilidades e valores/atitudes) a preocupação com a metodologia de 
trabalho, por parte do professor, é fundamental no momento de planejar as ações e as finalidades a serem alcançadas no processo de ensinoaprendizagem. De acordo com os Referenciais Curriculares Nacionais da Educação Profissional de Nível Técnico, a metodologia não é artifício, mas questão essencial. Isso porque, a metodologia deverá identificar-se com as "ações ou o processo de trabalho do sujeito que aprende, processo este desencadeado por desafios, problemas e/ou projetos propostos pelo professor e por este monitorado, orientado e assessorado" (Brasil. MEC, 2000, p. 31).

Segundo Barbosa, Gontijo e Santos (2004), pensar a educação profissional numa perspectiva de formação de competências requer inovações pedagógicas. Assim, torna-se possível o desenvolvimento de um processo de formação cuja finalidade seja,

além do domínio operacional de um determinado fazer, a compreensão global do processo produtivo, com a apreensão do saber tecnológico, a valorização da cultura do trabalho e a mobilização dos valores necessários à tomada de decisões. (Brasil. CNE/CEB. Parecer no 16, 1999, p. 8).

Para isso, torna-se necessário optarmos por estratégias de ensino que possibilitem alcançar tais pressupostos.

Portanto, o planejamento de situações de aprendizagem que envolvem a realização de atividades de estudo com objetivos claros e que têm relações com o mundo do trabalho torna-se essencial em todos os níveis de ensino. No nosso caso, tais atividades foram planejadas tendo como base metodológica as dinâmicas de grupos. Isso possibilitou o desenvolvimento, na educação profissional técnica de nível médio, de ações e operações pelos estudantes envolvendo conhecimentos, habilidades e valores/atitudes dos futuros profissionais, de maneira direta com o mundo do trabalho.

Em síntese, as atividades de dinâmicas de grupo realizadas trouxeram nelas agregadas saberes cognitivos, psicomotores e socioafetivos. Nesse sentido, para que sejam desenvolvidas habilidades e competências que reflitam na atuação profissional, tais competências devem trazer como condição a possibilidade de os estudantes alocarem esses saberes (cognitivos, psicomotores e socioafetivos) como recursos que os permitam, por meio de análises, sínteses, inferências, generalizações, analogias, associações e transferências, se envolverem em ações próprias de um contexto profissional específico, gerando um desempenho mais eficaz na prática profissional (Brasil. MEC, 2000).

\section{Referências bibliográficas}

ALBERTO, Maria de Fátima Pereira et al. Dinâmicas de grupo: instrumentos no processo de formação de agentes sociais. Disponível em: <http://www.prac.ufpb.br/anais/Icbeu_anais/anais/trabalho/ dinamicas.pdf $>$. Acesso em: 23 jun. 2011. 
BALBINOT, Edemar et al. A percepção e a auto-percepção desenvolvidas por dinâmicas de grupo. Revista Eletrônica de Contabilidade, v. 1; n. 3, mar./maio 2005. Disponível em: <w3.ufsm. $\mathrm{br} /$ revistacontabeis/anterior/artigos/vIIn01/a03vIIno1.pdf $>$. Acesso em: maio 2011.

BARBOSA, E. F.; GONTIJO, A. F.; SANTOS, F. F. O método de projetos na educação profissional ampliando as possibilidades na formação de competências. Educação em Revista, Belo Horizonte, MG, n. 40, p. 187212, dez. 2004.

BRASIL. Conselho Nacional de Educação (CNE). Câmara de Educação Básica (CEB). Resolução $n^{\circ} 4$, de 8 de dezembro de 1999. Institui as Diretrizes Curriculares Nacionais para a Educação Profissional de Nível Técnico. 23 p. Disponível em: <http://portal.mec.gov.br/dmdocuments/ rceb004_99.pdf>

BRASIL. Conselho Nacional de Educação (CNE). Câmara de Educação Básica (CEB). Parecer no 16, de 5 de outubro de 1999. Assunto:

Diretrizes Curriculares Nacionais para a Educação Profissional de Nível Técnico. 88 p. Disponível em: < http://portal.mec.gov.br/cne/arquivos/ pdf/1999/pceb016_99.pdf>

BRASIL. Ministério da Educação (MEC). Educação profissional: Referenciais Curriculares Nacionais para Educação Profissional de Nível Técnico: Introdução. Brasília: MEC, 2000. Disponível em: < http:// portal.mec.gov.br/setec/arquivos/pdf/introduc.pdf $>$.

COLTRO, Alex. Apostila 04: as relações humanas: o mundo social organizado. Piracicaba, SP: Escola Superior de Agricultura "Luiz de Queiroz", Departamento de Economia, Administração e Sociologia, 2006. Disponível em: <www.economia.esalq.usp.br/intranet/ uploadfiles/1016.doc $>$.

DAVIDOV, Vasili. La enseñanza escolar y el desarollo psiquico: investigación psicológica teórica y experimental. Moscu: Progresom, 1988.

FRANCO, Maria Amélia Santoro. Pedagogia da pesquisa-ação. Revista Educação e Pesquisa, São Paulo, v. 31, n. 3, p. 483-502, set./dez. 2005. Disponível em: <www.scielo.br/pdf/ep/v31n3/a11v31n3.pdf>. Acesso em: 20 maio 2011.

FREIRE, Paulo. Pedagogia do oprimido. Rio de Janeiro: Paz e Terra, 1987.

LEONTIEV, Alexis. O desenvolvimento do psiquismo. Lisboa: Horizonte Universitário, 1978.

LEWIN, Kurt. The dynamics of group action. Educational Leadership, p. 195-200, Jan. 1944. Disponível em: < http://www.ascd.org/ASCD/pdf/ journals/ed_lead/el_194401_lewin.pdf>. 
PERPÉTUO, Susan Chio de; GONÇALVEZ, Ana Maria. Dinâmicas de grupos na formação de lideranças. Rio de Janeiro: DP\&A, 2005.

SAITO, Carlos Hiroo. Por que investigação-ação, empowerment e as idéias de Paulo Freire se integram. In: MION, Rejane Aurora; SAITO, Carlos Hiroo (Org.). Investigação-ação: mudando o trabalho de formar professores. Ponta Grossa: Planeta, 2001.

SILVA, Jorge Antonio Peixoto da. O uso de dinâmicas de grupo em sala de aula: um instrumento de aprendizagem experiencial esquecido ou ainda incompreendido? Revista Saber Científico, Porto Velho, v. 1, n. 2, p. 82-89, jul./dez., 2008. Disponível em: <www.saolucas.edu.br/ revista/index.php/resc/article/view/22/ED25 > . Acesso em: jun. 2011.

SOCIEDADE BRASILEIRA DE DINÂMICAS DE GRUPO (SBDG).

Dinâmica de grupo: conhecendo a história da dinâmica dos grupos no Brasil. Blumenau: SBDG, 2006.

TAVARES, C.; LIRA, N. (Org.). Construindo uma cultura de paz: oficinas pedagógicas. Recife: Comunigraf, 2001.

Taís Fim Alberti, doutora em Educação pela Universidade Federal do Rio Grande do Sul (UFRGS), é professora adjunta 2 do Núcleo de Tecnologia Educacional (NTE) da Universidade Federal de Santa Maria (UFSM) e professora-pesquisadora I da Universidade Aberta do Brasil (UAB/UFSM). Compõe a equipe multidisciplinar da UAB/UFSM, Santa Maria, Rio Grande do Sul, Brasil.

taisfim@nte.ufsm.br

Ilse Abegg, doutora em Informática na Educação pela Universidade Federal do Rio Grande do Sul (UFRGS), é pesquisadora da Fundação de Amparo à Pesquisa do Estado do Rio Grande do Sul (Fapergs), professorapesquisadora II da Universidade Aberta do Brasil (UAB/UFSM) e professora colaboradora do Programa de Pós-Graduação em Educação da UFSM, Santa Maria, Rio Grande do Sul, Brasil.

ilse.abegg@ufsm.br

Márcia Rejane Julio Costa, doutoranda em Educação em Ciências: Química da Vida e Saúde na Universidade Federal do Rio Grande do Sul (UFRGS), é professora do Colégio Politécnico da Universidade Federal de Santa Maria (UFSM), Santa Maria, Rio Grande do Sul, Brasil.

jhiwamar@hotmail.com

Mauro Titton, doutor em Educação pela Universidade Federal da Bahia (UFBA), é professor do curso de Pedagogia no Departamento de Metodologia de Ensino/Centro de Ciências da Educação da Universidade Federal de Santa Catarina(UFSC), Florianópolis, Santa Catarina, Brasil.

maurotitton@gmail.com

Recebido em 25 de junho de 2013.

Aprovado em 11 de março de 2014. 